\title{
Alcohol Consumption and Risk of All-Cause and Cardiovascular Disease Mortality in Men
}

\author{
Erin K. Howie, ${ }^{1}$ Xuemei Sui, ${ }^{1}$ Duck-chul Lee, ${ }^{1}$ Steven P. Hooker, ${ }^{1,2}$ \\ James R. Hébert, ${ }^{3}$ and Steven N. Blair ${ }^{1,3}$ \\ ${ }^{1}$ Department of Exercise Science, Arnold School of Public Health, University of South Carolina, Columbia, SC, USA \\ ${ }^{2}$ Prevention Research Center, University of South Carolina, Columbia, SC, USA \\ ${ }^{3}$ Cancer Prevention and Control Program and Department of Epidemiology and Biostatistics, Arnold School of Public Health, \\ University of South Carolina, Columbia, SC, USA
}

Correspondence should be addressed to Erin K. Howie, howieek@email.sc.edu

Received 26 January 2011; Accepted 9 May 2011

Academic Editor: Leonard W. Poon

Copyright (๑) 2011 Erin K. Howie et al. This is an open access article distributed under the Creative Commons Attribution License, which permits unrestricted use, distribution, and reproduction in any medium, provided the original work is properly cited.

\begin{abstract}
This study examined the association between consumption of alcoholic beverages and all-cause and cardiovascular disease (CVD) mortality in a cohort of men $(n=31,367)$. In the Cox proportional hazards model adjusted for age, year of examination, body mass index (BMI), smoking, family history of CVD, and aerobic fitness, there were no significant differences in risk of all-cause mortality across alcohol intake groups. Risk of CVD mortality was reduced $29 \%$ in quartile 1 (HR $=0.71,95 \%$ confidence interval (CI): $0.53,0.95)$ and $25 \%$ in quartile $2(\mathrm{HR}=0.75,95 \% \mathrm{CI}: 0.58,0.98)$. The amount of alcohol consumed to achieve this risk reduction was $<6$ drinks/week; less than the amount currently recommended. The addition of other potential confounders and effect modifiers including blood pressure, insulin sensitivity, lipid levels, and psychological variables did not affect the magnitude of association. Future research is needed to validate the current public health recommendations for alcohol consumption.
\end{abstract}

\section{Introduction}

Light-to-moderate alcohol consumption has been shown in several prospective studies to reduce the risk of all-cause mortality and several cardiac outcomes, including cardiovascular disease (CVD) mortality in men [1-10]. Several hypotheses exist for the mechanism of this protective effect including increased exposure to antioxidants, improved lipid profiles, reduced insulin resistance, decreased blood coagulation, and modified inflammation pathways $[11,12]$.

Despite a large number of studies examining alcohol consumption and mortality, questions remain about the nature of this relationship. Three primary concerns include the influence of confounding factors, appropriate public health recommendations, and differential effects between types of alcohol $[13,14]$. Selection bias is a particular concern when comparing nondrinkers to drinkers. Nondrinkers may abstain from alcohol because of an initial health condition and be more likely to have other conditions that might confound the relationship including obesity, physical inactivity, and overall health problems [14]. In addition, moderate alcohol consumption has been associated with positive psychosocial outcomes including sociability and stress reduction, which may further confound the association with mortality $[15,16]$. Confounding is a limitation of nonexperimental studies, yet it is unethical and impractical to conduct long-term randomized controlled trials of alcohol consumption. In an attempt to address this challenge, investigators have used statistical methods to control for possible confounders that may increase the risk of mortality independent of alcohol consumption, but that may be differentially distributed in those who drink alcohol versus those who do not, such as smoking or physical inactivity.

Several problems have hampered the ability to construct an appropriate public health message about alcohol consumption. Methodological variation has led to inconsistent estimates of protective amounts of alcohol and, thus, an inability to quantify safe recommendations [17]. In addition, any protective effect must simultaneously be weighed against 
potential negative consequences. While several studies support light-to-moderate alcohol consumption as a protective factor against CVD and all-cause mortality, excessive alcohol intake has been associated with increased triglycerides, high blood pressure, risk of some cancers, liver cirrhosis, heart failure, and all-cause mortality $[9,12,18]$. Also, certain cancers (e.g., breast) may be associated with increased risk at low doses, but no dose response thereafter [19-21]. As a result of these conflicting messages, the public may be confused about the relationship between alcohol and health outcomes.

The purpose of this study was to analyze the relationship between alcohol consumption and all-cause and CVD mortality in a cohort of men while considering a variety of potential confounding and modifying risk factors. Additionally, differential effects of types of alcohol on these health outcomes were investigated.

\section{Materials and Methods}

2.1. Study Participants. Study participants were from the Aerobics Center Longitudinal Study (ACLS) [22], a prospective epidemiological study of health outcomes in USA adults. The sample for the current analyses was limited to men, the majority of whom were white, middle to upper income, received a baseline examination at the Cooper Clinic in Dallas, Texas between 1974 and 2002 with at least one year of followup, were aged $\geq 20$ years at baseline, were free of known CVD, cancer, or abnormal ECG, and had complete information on alcohol intake and maximal exercise treadmill test. Individuals participating in the ACLS were either referred to the clinic by their employers or physicians or through self-referral. The study was annually reviewed and approved by the Cooper Institute Institutional Review Board, and all participants gave written informed consent for the baseline clinical examination and follow-up.

2.2. Primary Exposure Variable. Alcohol intake in drinks per week among participants was self-reported at baseline. Participants were asked, "How many 12-ounce drinks of beer, 3-ounce drinks of wine (5-ounce drinks of wine during more recent data collection cycles), and/or 1.5-ounce drinks of hard liquor do you consume per week?" Self-report alcohol intake has been previously validated against dietary records in men $(r=0.86)[23,24]$. Participants were then classified either as nondrinkers, or in quartiles of drinkers based on baseline alcohol drinking reports.

2.3. Outcome Variables. All participants were followed from the date of their baseline examination until their death or December 31, 2003. Mortality surveillance was primarily through the National Death Index. CVD mortality was defined as the International Classification of Diseases, Ninth Revision codes 390 to 449.9 before 1999 and Tenth Revision codes I00 to I78 during 1999-2003.

2.4. Covariates. The baseline clinical assessment has been previously described in detail $[22,25,26]$. At the baseline visit patients completed a written survey and anthropometric, blood pressure, blood chemistry, and electrocardiogram measures. Body Mass Index [BMI $=$ weight $(\mathrm{kg}) /$ height $\left.(\mathrm{m})^{2}\right]$ was calculated from height and weight. Resting blood pressure was assessed via ascultatory method [27]. Blood samples were drawn after a 12-hour overnight fast, and analyzed for fasting glucose and cholesterol using automated bioassays according to the Centers for Disease Control and Prevention Lipid Standardization Program. Hypertension, hypercholesterolemia, and diabetes were defined according to clinical thresholds or self-reported as a previous diagnosis from a physician. Hypertension was defined as resting systolic or diastolic blood pressure $\geq 140 / 90 \mathrm{mmHg}$, hypercholesterolemia was defined as total cholesterol $\geq 240 \mathrm{mg} / \mathrm{dL}$ [28], and diabetes was defined as fasting glucose $\geq 126 \mathrm{mg} / \mathrm{dL}$ [29]. The questionnaire included questions on smoking habits, family history of CVD, and the presence of neuropsychiatric conditions including anxiety, depression, suicidal thoughts, or psychological counseling. Cardiorespiratory fitness (CRF) was assessed using symptom-limited maximal treadmill time during the modified Balke Protocol [22, 30]. Test termination occurred by participant volition or physician determined medical reasons. Test duration has been strongly correlated with maximal oxygen uptake $(r=0.92)$ [31]. Cardiorespiratory fitness is a quantifiable, objective measure with stronger associations to future health outcomes than self-reported physical activity [32]. Treadmill times were classified into fitness quintiles with the first quintile classified as unfit and the remaining four quintiles as fit [33].

2.5. Statistical Analysis. Cox proportional hazards models were used to calculate hazard ratios (HRs) and associated 95\% confidence intervals. Alcohol consumption was the primary exposure of interest. All-cause and CVD mortality were fit as the outcomes (i.e., death or not, and time to event or censoring) for survival analysis. Nondrinkers were used as the referent group and those classified as drinkers were categorized into quartiles of exposure. Linear and quadratic trends were tested by fitting the continuous variable of alcohol consumption in the basic model for both all-cause and cardiovascular disease mortality. The basic model was adjusted for age (in years), year of examination, BMI, smoking (current smoker or not), family history of CVD (yes or no), and treadmill time (minutes). Because blood pressure [34], insulin sensitivity [35], and lipid levels [36] have been shown to mediate the relationship between alcohol and CVD mortality, they were added individually and then simultaneously into the basic model. Finally, the full model was adjusted for psychological variables $[15,16]$.

To examine effect modification due to other health risk factors, multivariate stratified analyses were conducted for dichotomies based on age ( $<60$ and $\geq 60$ years), BMI $\left(<25\right.$ and $\geq 25 \mathrm{~kg} / \mathrm{m}^{2}$ ), health status (healthy and unhealthy defined as having at least one of the following diseases: hypertension, diabetes, or hyperlipidemia), and fitness (least fit $20 \%$ and most fit $80 \%$ ) to test for effect modification. These models were adjusted for year of examination, smoking, family history of CVD, and age, BMI, health status, and fitness where appropriate. 
After analyzing the overall effect of alcohol on mortality, separate analyses were run for each type of alcohol (beer, wine, and liquor), because of the potential differential effects from different types of alcohol. As there were few men who consumed a single beverage type, analysis was conducted separately for quartiles of a single type of alcohol while adjusting for the remaining type of alcohol consumption $[37,38]$. Alcohol consumption quartiles were created independently for each alcohol type and hazard ratios adjusted for age, year of examination, BMI, smoking, family history of CVD, maximal treadmill time, and remaining types of alcohol were calculated using nondrinkers as the reference group.

\section{Results and Discussion}

A total of 31,637 men were included in the sample. The mean age of men at baseline was 42.9 (standard deviation (SD): 9.2) years. Baseline characteristics are presented in Table 1.

Mean follow-up time was 16.0 (8.3) years for a total of 504,735 person-years. There were 1,834 total deaths and 588 CVD deaths. The rate of all-cause and CVD mortality was calculated for the five drinking categories: nondrinkers, quartile 1 (1-3 drinks/week), quartile 2 (4-6 drinks/week), quartile 3 (7-13 drinks/week), and quartile 4 ( $\geq 14$ drinks/week). Alcohol consumption was linearly associated with both all-cause and CVD mortality rate $(P=$ 0.002 and $P=0.02$ ).

3.1. Primary Analysis. In the basic model adjusted for age, year of examination, BMI, smoking, family history of CVD, and fitness, there were no significant differences in all-cause mortality risks across alcohol intake groups (Table 2). There was a lower risk of CVD mortality in quartile $1(\mathrm{HR}=0.71$, $95 \%$ confidence interval $(\mathrm{CI}): 0.53,0.95)$ and quartile 2 (HR $=0.75,95 \%$ CI: $0.58,0.98)$ in the basic model which is less than 6 drinks per week (see Table 3). The addition of potential intermediate variables of glucose, lipids, and blood pressure, or the inclusion of all three, did not attenuate these relationships. The additional adjustment for psychological variables did not alter the observed associations and are not included in the results presented.

3.2. Stratified Analysis. The lower risk of all-cause mortality from light drinking (quartile 1) was attenuated when the results were stratified by BMI, health status, and fitness (see Table 4). However, men younger than 60 years in quartile 1 exhibited a significantly lower risk of all-cause mortality (HR $=0.80,95 \%$ CI: $0.66,0.96$ ); whereas, men 60 or older did not.

For CVD mortality, there were no significant findings in men who were $\geq 60$ years, had a BMI $<25 \mathrm{~kg} / \mathrm{m}^{2}$, were healthy, or unfit (see Table 5). Younger men had lower risk of CVD mortality in quartile 1 ( $\mathrm{HR}=0.59,95 \% \mathrm{CI}: 0.43,0.83$ ) and quartile 2 (HR $=0.70,95 \% \mathrm{CI}: 0.52,0.93)$. Men with a BMI $\geq 25 \mathrm{~kg} / \mathrm{m}^{2}$ had lower CVD mortality risk in quartile 1 $(\mathrm{HR}=0.67,95 \% \mathrm{CI}: 0.47,0.94)$ and quartile $2(\mathrm{HR}=0.71$, $95 \%$ CI: $0.52,0.97)$. Unhealthy men had a reduced risk in quartile 3 ( $\mathrm{HR}=0.74,95 \% \mathrm{CI}$ : $0.54,0.998)$. When stratified by fitness, fit men exhibited a lower risk in quartile $2(\mathrm{HR}=$ $0.69,95 \%$ CI: $0.49,0.96)$.

3.3. Type of Alcohol. The results of the sensitivity analysis are listed in Table 4 . There were a total of 26,767 drinkers, of which 23,728 reported drinking beer, 21,997 reported drinking wine, and 20,416 reported drinking liquor. Therefore, for this analysis, the types of alcohol drinking are not exclusive. For all-cause mortality, there were no significant differences in risk for any three of the alcohol types in comparison to nondrinkers (see Table 6). For CVD mortality, there was a lower risk with beer consumption in quartile $3(\mathrm{HR}=0.72$, $95 \%$ CI: $0.52,0.995)$, wine consumption in quartile 2 ( $\mathrm{HR}=$ $0.70,95 \%$ CI: $0.53,0.93)$ and liquor consumption in quartile $2(\mathrm{HR}=0.71,95 \% \mathrm{CI}: 0.50,0.93)$ and Q3 (HR $=0.69,95 \%$ CI: $0.55,0.93$ ) (see Table 7).

\section{Discussion}

4.1. All-Cause Mortality. In the current study, the relationship between risk of all-cause mortality with alcohol consumption appeared to evince a flattened J-shaped curve pattern. However, the risk reductions were significant only at the lowest levels of alcohol consumption. Other studies reporting on the association of alcohol consumption and all-cause mortality in men have found protective effects up to three drinks per day [5]. In the Physicians Health Study, Gaziano et al [3], found a reduction in all-cause mortality with 5 to 6 drinks/week and reductions in CVD mortality with all levels of alcohol consumption. Gaziano's results are consistent with a meta-analysis conducted by Di Castelnuovo [39] which found a reduced risk for all-cause mortality up to 4 drinks per day.

4.2. Cardiovascular Disease Mortality. It has been hypothesized that the lower CVD mortality risk associated with limited alcohol intake is due to the cardioprotective effects of alcohol such as improved lipid profiles and decreased blood coagulation $[11,12]$. CVD contributes to $34.3 \%$ of all deaths in the nation and is an important health outcome [40]; therefore, our results warrant consideration. In this sample, $32 \%$ of all deaths were attributed to CVD, similar to the nationwide estimates. There was a $29 \%$ and $25 \%$ reduction in risk for CVD mortality in the first and second quartiles of alcohol consumption, respectively. This risk reduction was found for 1-6 drinks per week. The lower risk of CVD death may be balanced with an increase in other causes of death potentially due to alcohol consumption, again complicating public health recommendations.

The lower CVD mortality risk we observed was not attenuated when potential intermediate factors of blood pressure, lipids, and glucose were added to the model, suggesting the lower risks were not mediated by these factors. While Suh et al. [7] and Djoussé et al. [41] found that the reduced risk of CVD mortality in women was mediated by lipids and insulin sensitivity, other authors have found the relationship to be independent of these risk factors. Arriola et al. [1] found that blood pressure, cholesterol, and diabetes did not alter 
TABle 1: Baseline demographics by alcohol consumption level, Aerobics Center for Longitudinal Study (ACLS), $1974-2002$.

\begin{tabular}{|c|c|c|c|c|c|}
\hline & \multicolumn{5}{|c|}{ Alcohol consumption (drinks/week) } \\
\hline & Nondrinkers $(0)$ & Quartile 1 (1-3) & Quartile 2 (4-6) & Quartile 3 (7-13) & Quartile $4(\geq 14)$ \\
\hline$n$ & 4870 & 6733 & 6150 & 6841 & 7043 \\
\hline Age (years) & $43.63(9.65)$ & $42.15(9.15)$ & $42.34(9.07)$ & $42.95(9.23)$ & $43.62(9.13)$ \\
\hline Alcohol (drinks/week) & 0 & $2.01(0.76)$ & $5.00(0.87)$ & $9.65(1.93)$ & $24.62(13.64)$ \\
\hline Body mass index $\left(\mathrm{kg} / \mathrm{m}^{2}\right)$ & $26.65(4.29)$ & $26.63(4.02)$ & $26.36(3.65)$ & $26.28(3.45)$ & $26.42(3.35)$ \\
\hline Maximal treadmill time (min) & $17.24(5.15)$ & $18.33(4.89)$ & $18.14(4.90)$ & $18.50(4.84)$ & $17.78(4.83)$ \\
\hline Current smokers (\%) & 10.62 & 14.18 & 19.50 & 22.03 & 29.09 \\
\hline Systolic blood pressure (mmHg) & $121(13)$ & $121(13)$ & $121(13)$ & $121(13)$ & $122(13)$ \\
\hline Diastolic blood pressure (mmHg) & $81(10)$ & $80.91(9.47)$ & $80.52(9.35)$ & $81.17(9.41)$ & $81.90(9.53)$ \\
\hline Hypertension $(\%)^{\mathrm{a}}$ & 30.86 & 28.32 & 28.10 & 30.35 & 34.49 \\
\hline Fasting glucose (mg/dL) & $99.14(18.92)$ & $99.20(16.52)$ & $98.80(14.50)$ & $99.74(14.50)$ & $101.13(14.19)$ \\
\hline Diabetes $(\%)^{\mathrm{b}}$ & 4.58 & 4.92 & 4.70 & 4.37 & 4.91 \\
\hline Total cholesterol (mg/dL) & $205.80(38.56)$ & $203.21(39.88)$ & $205.42(38.29)$ & $209.58(39.16)$ & $217(40.42)$ \\
\hline Triglycerides (mg/dL) & $141.09(104.59)$ & $137.20(106.77)$ & $132.02(94.37)$ & $134.63(101.78)$ & $144.54(105.24)$ \\
\hline Hyperlipidemia $(\%)^{\mathrm{c}}$ & 29.49 & 26.56 & 26.03 & 28.46 & 35.57 \\
\hline Unhealthy $(\%)^{\mathrm{d}}$ & 49.63 & 46.81 & 45.69 & 48.68 & 55.93 \\
\hline Family history of CVD (\%) & 26.96 & 23.91 & 25.45 & 24.69 & 28.44 \\
\hline
\end{tabular}

${ }^{a}$ Defined as systolic or diastolic blood pressure $\geq 140 / 90 \mathrm{mmHg}$ or history of physician diagnosis.

${ }^{b}$ Defined as fasting glucose $\geq 126 \mathrm{mg} / \mathrm{dl}$ or history of physician diagnosis.

${ }^{c}$ Defined as fasting total cholesterol $\geq 240 \mathrm{mg} / \mathrm{dl}$ or triglyceride $\geq 200 \mathrm{mg} / \mathrm{dL}$.

${ }^{\mathrm{d}}$ Defined as presence of one or more of following diseases: hypertension, diabetes, or hyperlipid.

TABle 2: Hazard ratios of all-cause mortality by alcohol consumption level in men, Aerobics Center for Longitudinal Study (ACLS), 19742002.

\begin{tabular}{|c|c|c|c|c|c|}
\hline & \multicolumn{5}{|c|}{ Alcohol consumption (drinks/week) } \\
\hline & Nondrinkers $(0)$ & Quartile 1 (1-3) & Quartile 2 (4-6) & Quartile $3(7-13)$ & Quartile $4(\geq 14)$ \\
\hline Person-years & 86,872 & 91,529 & 98,303 & 103,625 & 124,360 \\
\hline No. & 4870 & 6733 & 6150 & 6841 & 7043 \\
\hline No. of Deaths & 343 & 237 & 350 & 349 & 555 \\
\hline Death rate ${ }^{\mathrm{a}}$ & 43.8 & 37.2 & 43.3 & 41.6 & 51.2 \\
\hline Basic model ${ }^{\mathrm{b}}$ & 1.00 (referent) & $0.86(0.73-1.01)$ & $0.95(0.82-1.10)$ & $0.97(0.83-1.12)$ & $1.09(0.95-1.25)$ \\
\hline \multicolumn{6}{|l|}{ Basic model plus } \\
\hline Blood pressure factors ${ }^{\mathrm{c}}$ & 1.00 (referent) & $0.86(0.73-1.02)$ & $0.94(0.81-1.09)$ & $0.97(0.83-1.12)$ & $1.06(0.92-1.21)$ \\
\hline Fasting glucose factors ${ }^{\mathrm{d}}$ & 1.00 (referent) & $0.84(0.71-0.99)$ & $0.95(0.82-1.10)$ & $0.96(0.82-1.11)$ & $1.07(0.94-1.23)$ \\
\hline Lipid factors ${ }^{\mathrm{e}}$ & 1.00 (referent) & $0.86(0.73-1.01)$ & $0.95(0.82-1.11)$ & $0.96(0.83-1.12)$ & $1.09(0.95-1.25)$ \\
\hline All intermediate factors ${ }^{\text {cde }}$ & 1.00 (referent) & $0.84(0.71-0.99)$ & $0.94(0.81-1.09)$ & $0.96(0.82-1.11)$ & $1.05(0.91-1.20)$ \\
\hline
\end{tabular}

${ }^{a}$ Death rate per 10,000 person-years adjusted for age (in years).

${ }^{\mathrm{b}}$ Adjusted for age (in years), year of examination, BMI ( $\left.\mathrm{kg} / \mathrm{m}^{2}\right)$, smoking (current smoker or not), family history of CVD (yes or no), and maximal treadmill time (min).

'Systolic blood pressure and reported hypertension (yes or no).

${ }^{\mathrm{d}}$ Fasting glucose and reported diabetes (yes or no).

eTotal cholesterol and triglyceride.

their results and, through coronary angiography, Femia et al. [42] found the risk for atherosclerosis and cardiac mortality was independent of cholesterol, hypertension, and diabetes. More research is needed to study the potential mechanisms of alcohol intake on reduced CVD mortality risk.

4.3. Public Health Recommendations. Our results do not support the currently recommended intake of 1-2 drinks per day for men from the American Heart Association [43]. The lower alcohol consumption for risk reduction in our study may result from complete adjustment for confounders including fitness and thorough screening resulting in exclusion of preclinical cases. There are large variations in results from prospective studies examining alcohol consumption and mortality making it difficult to compare findings for universal alcohol recommendations. In Di Castelnuovo et al.'s [39] meta-analysis of all-cause mortality, they found differences among genders, countries of the study, and number of confounders. There has been large variation in methods of reporting and categorizing alcohol consumption. 
TABle 3: Hazard ratios of CVD mortality by alcohol consumption level in men, Aerobics Center for Longitudinal Study (ACLS), $1974-2002$.

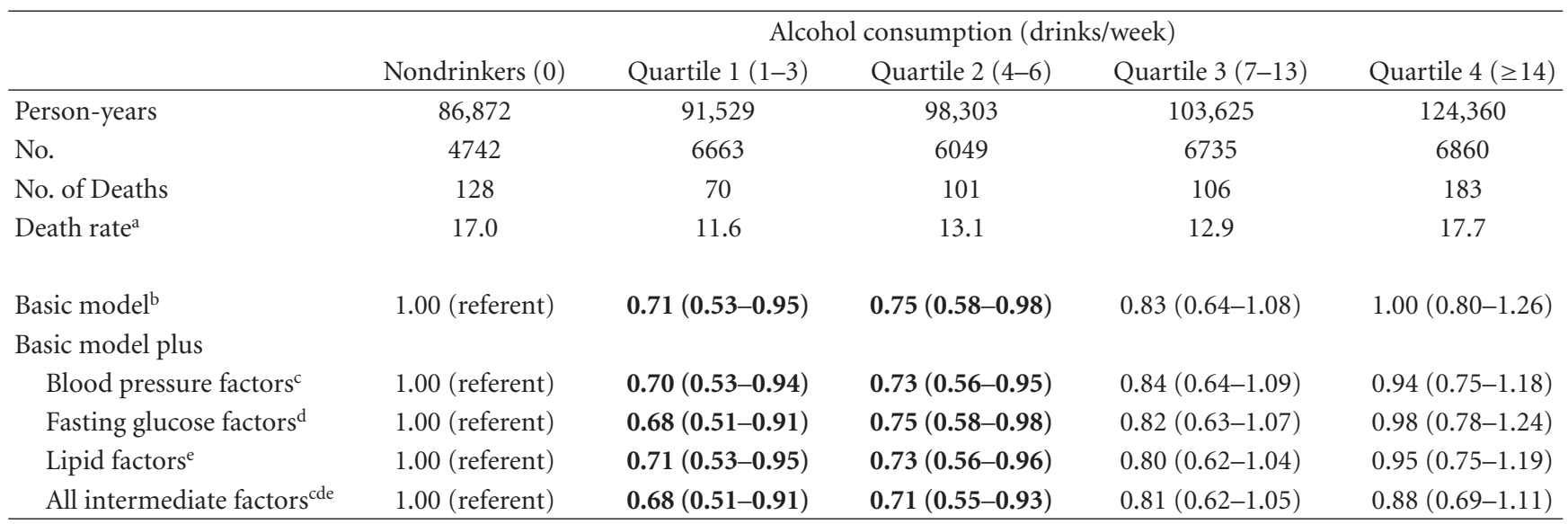

${ }^{a}$ Death rate per 10,000 person-years adjusted for age (in years).

${ }^{b}$ Adjusted for age (in years), year of examination, BMI $\left(\mathrm{kg} / \mathrm{m}^{2}\right)$, smoking (current smoker or not), family history of CVD (yes or no), and maximal treadmill time (min).

${ }^{\mathrm{c} S y s t o l i c}$ blood pressure and reported hypertension (yes or no).

${ }^{\mathrm{d}}$ Fasting glucose and reported diabetes (yes or no).

${ }^{\mathrm{e}}$ Total cholesterol and triglyceride.

TABLE 4: Hazard ratios of all-cause mortality stratified by risk factors ${ }^{\mathrm{a}}$, Aerobics Center for Longitudinal Study (ACLS), $1974-2002$.

\begin{tabular}{|c|c|c|c|c|c|}
\hline & \multicolumn{5}{|c|}{ Alcohol consumption (drinks/week) } \\
\hline & Nondrinkers $(0)$ & Quartile 1 (1-3) & Quartile 2 (4-6) & Quartile $3(7-13)$ & Quartile $4(\geq 14)$ \\
\hline \multicolumn{6}{|l|}{ Age } \\
\hline Age $<60(n=30,263)$ & 1.00 (referent) & $0.80(0.66-0.96)$ & $0.92(0.78-1.09)$ & $1.02(0.86-1.20)$ & $1.08(0.93-1.26)$ \\
\hline Age $\geq 60(n=1,374)$ & 1.00 (referent) & $0.86(0.59-1.25)$ & $0.85(0.59-1.23)$ & $0.75(0.52-1.08)$ & $1.04(0.76-1.44)$ \\
\hline \multicolumn{6}{|l|}{ BMI } \\
\hline $\mathrm{BMI}<25(n=12,037)$ & 1.00 (referent) & $0.85(0.65-1.11)$ & $1.03(0.80-1.32)$ & $0.95(0.74-1.22)$ & $0.97(0.77-1.23)$ \\
\hline $\mathrm{BMI} \geq 25(n=19,600)$ & 1.00 (referent) & $0.86(0.70-1.06)$ & $0.90(0.75-1.09)$ & $0.96(0.79-1.16)$ & $1.12(0.95-1.33)$ \\
\hline \multicolumn{6}{|l|}{ Health status ${ }^{\mathrm{b}}$} \\
\hline Healthy $(n=15,989)$ & 1.00 (referent) & $0.91(0.69-1.20)$ & $0.92(0.71-1.19)$ & $1.10(0.86-1.42)$ & $1.11(0.87-1.41)$ \\
\hline Unhealthy $(n=15,648)$ & 1.00 (referent) & $0.82(0.67-1.01)$ & $0.97(0.81-1.17)$ & $0.88(0.73-1.07)$ & $1.05(0.89-1.24)$ \\
\hline \multicolumn{6}{|l|}{ Fitness level } \\
\hline Unfit (least fit $20 \%)(n=5,238)$ & 1.00 (referent) & $0.91(0.67-1.22)$ & $1.02(0.79-1.32)$ & $1.10(0.83-1.44)$ & $1.17(0.92-1.48)$ \\
\hline Fit (most fit $80 \%)(n=26,399)$ & 1.00 (referent) & $0.84(0.69-1.03)$ & $0.91(0.76-1.10)$ & $0.87(0.73-1.05)$ & $1.01(0.85-1.19)$ \\
\hline
\end{tabular}

adjusted for year of examination, smoking (current smoker or not), family history of CVD (yes or no), and each other factor in the table.

${ }^{b}$ Defined as presence or absence of one or more of following diseases: hypertension, diabetes, or hyperlipidemia.

Various authors have used different definitions of drinks ranging from 8 grams of alcohol per drink [10] to 22.8 grams [6]. Therefore, we did not attempt to impose grams of alcohol conversion factors on self-reported drinks per week. There is additional complexity when looking at the myriad of cardiovascular outcomes. Previous studies have used various outcomes including CVD mortality, cardiac mortality, CHD, and myocardial infarction. For example, Beulens et al. [37] found a reduction in risk of myocardial infarction, but not in all-cause or CVD mortality. Due to such variation, it is challenging to establish widespread recommendations for a safe or protective amount of alcohol consumption as related to $\mathrm{CV}$ health.

While a decrease in risk of all-cause mortality with alcohol consumption was not found in this sample, there was not a significantly increased risk with the highest amounts of self-reported alcohol consumption. Klatsky [12] defined heavy drinking as greater than 3 drinks per day, which is consistent with the mean 24 drinks per week found in the highest quartile of alcohol consumption in this study. While our sample did not show a higher risk of either all-cause or CVD mortality with the highest alcohol consumption, there are other concerns in recommending drinking alcohol including potential alcohol abuse. Rehm et al. [44] estimated $12.1 \%$ of disability-adjusted life years for men in the US were attributed to alcohol-related causes with an estimated cost of $\$ 235$ billion dollars. Of problem drinkers, $82 \%$ report drinking the moderate amount recommended to protect against CVD [17]. Alcohol may be harmful in many ways, even in small amounts (e.g., as a cocarcinogen with tobacco smoke) [45]. 
TABLE 5: Hazard ratios of CVD mortality stratified by risk factors ${ }^{\mathrm{a}}$, Aerobics Center for Longitudinal Study (ACLS), $1974-2002$.

\begin{tabular}{|c|c|c|c|c|c|}
\hline & \multicolumn{5}{|c|}{ Alcohol consumption (drinks/week) } \\
\hline & Nondrinkers $(0)$ & Quartile 1 (1-3) & Quartile 2 (4-6) & Quartile 3 (7-13) & Quartile $4(\geq 14)$ \\
\hline \multicolumn{6}{|l|}{ Age } \\
\hline Age $<60(n=30,263)$ & 1.00 (referent) & $0.59(0.43-0.83)$ & $0.70(0.52-0.93)$ & $0.78(0.58-1.04)$ & $0.85(0.66-1.11)$ \\
\hline Age $\geq 60(n=1,374)$ & 1.00 (referent) & $1.07(0.57-2.00)$ & $0.82(0.43-1.57)$ & $1.06(0.59-1.91)$ & $1.53(0.92-2.54)$ \\
\hline \multicolumn{6}{|l|}{ BMI } \\
\hline $\mathrm{BMI}<25(n=12,037)$ & 1.00 (referent) & $0.80(0.47-1.37)$ & $0.84(0.51-1.39)$ & $0.76(0.46-1.25)$ & $1.02(0.66-1.59)$ \\
\hline $\mathrm{BMI} \geq 25(n=19,600)$ & 1.00 (referent) & $0.67(0.47-0.94)$ & $0.71(0.52-0.97)$ & $0.82(0.60-1.11)$ & $0.91(0.69-1.19)$ \\
\hline \multicolumn{6}{|l|}{ Health status ${ }^{\mathrm{b}}$} \\
\hline Healthy $(n=15,989)$ & 1.00 (referent) & $0.61(0.32-1.16)$ & $0.73(0.42-1.28)$ & $1.06(0.63-1.79)$ & $1.18(0.72-1.92)$ \\
\hline Unhealthy $(n=15,648)$ & 1.00 (referent) & $0.73(0.52-1.01)$ & $0.76(0.56-1.02)$ & $0.74(0.54-0.998)$ & $0.90(0.69-1.17)$ \\
\hline \multicolumn{6}{|l|}{ Fitness level } \\
\hline Unfit (least fit 20\%) $(n=5,238)$ & 1.00 (referent) & $0.65(0.39-1.08)$ & $0.80(0.52-1.22)$ & $0.80(0.50-1.27)$ & $1.00(0.68-1.44)$ \\
\hline Fit (most fit $80 \%)(n=26,399)$ & 1.00 (referent) & $0.72(0.51-1.04)$ & $0.69(0.49-0.96)$ & $0.73(0.53-1.00)$ & $0.89(0.67-1.19)$ \\
\hline
\end{tabular}

${ }^{a}$ Adjusted for year of examination, smoking (current smoker or not), family history of CVD (yes or no), and each other factor in the table.

${ }^{b}$ Defined as presence or absence of one or more of following diseases: hypertension, diabetes, or hyperlipidemia.

TABLE 6: Hazard ratios of all-cause mortality stratified by types of alcohol beverage ${ }^{a}$, Aerobics Center for Longitudinal Study (ACLS), 19742002.

\begin{tabular}{|c|c|c|c|c|c|}
\hline & \multicolumn{5}{|c|}{ Alcohol consumption (drinks/week) } \\
\hline & Nondrinkers & Quartile 1 & Quartile 2 & Quartile 3 & Quartile 4 \\
\hline \multicolumn{6}{|l|}{$\operatorname{Beer}(n=23,728)$} \\
\hline No. & 4870 & 3854 & 4876 & 5779 & 4349 \\
\hline No. of Cases & 343 & 147 & 362 & 227 & 237 \\
\hline Hazard ratios & 1.00 (referent) & $0.87(0.71,1.06)$ & $0.99(0.84,1.16)$ & $0.90(0.75,1.07)$ & $1.15(0.96,1.37)$ \\
\hline \multicolumn{6}{|l|}{ Wine $(n=21,997)$} \\
\hline No. & 4870 & 4091 & 4999 & 4175 & 3862 \\
\hline No. of Cases & 343 & 177 & 370 & 183 & 196 \\
\hline Hazard ratios & 1.00 (referent) & $0.87(0.72,1.05)$ & $0.92(0.79,1.08)$ & $0.88(0.73,1.07)$ & $0.95(0.78,1.14)$ \\
\hline \multicolumn{6}{|c|}{ Liquor $(n=20,416)$} \\
\hline No. & 4870 & 3111 & 5022 & 3562 & 3851 \\
\hline No. of Cases & 343 & 126 & 383 & 247 & 423 \\
\hline Hazard ratios & 1.00 (referent) & $0.93(0.75,1.14)$ & $0.96(0.82,1.12)$ & $0.89(0.75,1.06)$ & $1.13(0.97,1.32)$ \\
\hline
\end{tabular}

ACLS: Aerobics Center Longitudinal Study.

${ }^{a}$ Adjusted for age (in years), year of examination, BMI $\left(\mathrm{kg} / \mathrm{m}^{2}\right)$, smoking (current smoker or not), family history of CVD (yes or no), maximal treadmill time (min), and remaining type of alcohol.

4.4. Stratified Analysis. The lower risk for all-cause mortality was attenuated when stratified by BMI and health status, but remained significant in younger men, consistent with stratified results found by Sun et al. [8]. A meta-analysis by Hvidtfeldt et al. [46] found a reduced risk of coronary heart disease in all ages, and our null findings in the older age group may be due to unequal sample size distributions for each level, reducing power in the sparser strata. The lower risk of CVD mortality in the current study remained in younger, overweight, unhealthy, and fit men. Similarly, the protective effect of alcohol consumption has been shown in populations with poor health status including men with hypertension [37], cardiovascular disease [47], and vascular disease including diabetes mellitus [2].

Interestingly, when the data were analyzed by fitness levels, fit men had lower risks of CVD mortality with larger alcohol consumption than did unfit men. This may be due to a synergistic effect as alcohol and fitness affect similar pathways such as lipid, glucose, and cholesterol metabolism. It also may be due to fit nondrinkers having a higher risk due to other latent variables (they may have been high risk and as a result began to exercise and quit drinking). The different risks associated with stratified populations confirm that the relationship between alcohol and mortality is complex and may vary between population subgroups.

4.5. Type of Alcohol. The results of the sensitivity analysis found no significant changes in risk of all-cause mortality when alcohol consumption was stratified by type, consistent with the overall analysis. Although for CVD mortality, our findings suggest that there was a reduction in risk of about $29 \%$ for moderate consumption of beer, wine, and liquor. This reduction was most consistent with liquor 
TABLE 7: Hazard ratios of CVD mortality stratified by types of alcohol beverage ${ }^{a}$, Aerobics Center for Longitudinal Study (ACLS), $1974-2002$.

\begin{tabular}{|c|c|c|c|c|c|}
\hline & \multicolumn{5}{|c|}{ Alcohol consumption (drinks/week) } \\
\hline & Non Drinkers & Quartile 1 & Quartile 2 & Quartile 3 & Quartile 4 \\
\hline \multicolumn{6}{|l|}{ Beer $(n=23,728)$} \\
\hline No. & 4870 & 3854 & 4876 & 5779 & 4349 \\
\hline No. of Cases & 128 & 43 & 104 & 64 & 75 \\
\hline Hazard ratios & 1.00 (referent) & $0.71(0.50,1.02)$ & $0.76(0.57,1.01)$ & $0.72(0.52,0.995)$ & $1.06(0.78,1.45)$ \\
\hline \multicolumn{6}{|c|}{ Wine $(n=21,997)$} \\
\hline No. & 4870 & 4091 & 4999 & 4175 & 3862 \\
\hline No. of Cases & 128 & 55 & 104 & 55 & 64 \\
\hline Hazard ratios & 1.00 (referent) & $0.76(0.55,1.05)$ & $0.70(0.53,0.93)$ & $0.74(0.53,1.04)$ & $0.89(0.64,1.23)$ \\
\hline \multicolumn{6}{|c|}{ Liquor $(n=20,416)$} \\
\hline No. & 4870 & 3111 & 5022 & 3562 & 3851 \\
\hline No. of Cases & 128 & 36 & 112 & 74 & 144 \\
\hline Hazard ratios & 1.00 (referent) & $0.74(0.51,1.07)$ & $0.71(0.55,0.93)$ & $0.69(0.50,0.93)$ & $0.98(0.75,1.27)$ \\
\hline
\end{tabular}

${ }^{a}$ Adjusted for age (in years), year of examination, BMI $\left(\mathrm{kg} / \mathrm{m}^{2}\right)$, smoking (current smoker or not), family history of CVD (yes or no), maximal treadmill time (min), and remaining type of alcohol.

consumption. Beulens et al. [37] also found that liquor drinkers had the strongest association with decreased risk of myocardial infarction. There have been inconsistencies, however, when comparing the types of alcohol on mortality. While several epidemiologic studies, including the current study, have found no differences in risk between types of alcohol consumed [1, 43, 48,49], others have suggested unique cardioprotection from wine [50]. Experimental studies have shown the ethanol in wine to have additional protection compared to dealcoholized red wine [51]. The differential effects may depend on gender. Compared to dealcoholized beverages, women had increased adiponectin (an anti-inflammatory factor also shown to be associated with improved insulin sensitivity) after drinking red wine, while men had increased levels after drinking liquor and beer [52].

4.6. Strengths and Limitations. Strengths of this study are inclusion of several potential confounders including measures of fitness and psychological variables, lengthy followup in a large cohort, exploration of relationships by health risk factors, and stratification by alcohol types. The limitations include that the sample was only men from the Cooper Clinic in Dallas, Tex, USA, predominantly white, and of middle to high incomes, limiting generalizations to entire populations. However, the homogenous population does eliminate potential confounding from gender [4] and race $[5,28]$, both of which have been shown to influence the relationship between alcohol and mortality. Additionally, this regional population is similar in physiologic variables to other North American populations [53]. The mean age of 43 at baseline with an average follow-up time of 16 years makes these findings particularly relevant for an aging American population. When stratified by age, we did not find a significant association in the older men, but this may have been due to a small sample of men above 60 . Future studies are needed to confirm the lower levels of alcohol consumption found to be protective in this study population.
Clearly, more work will be required in populations that differ in racial and ethnic composition to that of the ACLS.

While self-reported alcohol consumption has been validated [23], under or overreporting could have influenced the trends in risk reduction in either direction. The format of response did not allow assessment of varied drinking patterns including daily frequency of alcohol consumption. Studies have suggested that alcohol should be consumed in small amounts over multiple occasions for health benefits rather than binge drinking [54]. In the sensitivity analyses, it was not possible to isolate single types of drinkers due to low prevalence of single alcohol-type drinkers.

Despite adjustment for many confounders, confounding may still exist in this and other prospective studies. One potential confounder not adjusted for was diet, particularly fat intake, which plays an established role in cardiovascular outcomes. We did, however, measure and control for blood cholesterol levels which is associated with dietary fat intake [55].

Consistent with previous studies, we used nondrinkers as the referent group [5, 43, 56]. Some researchers have argued against using nondrinkers as the referent group due to confounding predisposing conditions or other latent variables contributing to differential mortality risk independent of alcohol consumption [10]. Mukamal et al. [14] found that nondrinkers are more likely to be in poor health, obese, of low income, or physically inactive; however, they did not exclude or report whether the participants had preexisting vascular disease. In contrast, when adjusted for preexisting disease (excluded or controlled for in our model), Wannamethee and Shaper [10] found ex-drinkers and lifelong nondrinkers had equal CVD mortality and almost equal all-cause mortality. When Hart and Smith [56] examined the health status of nondrinkers to drinkers, they did not differ substantially. Friesema et al. [57] found that the inverse relationship between alcohol consumption and mortality could not be explained by health status alone. Potential confounding would have a less likely effect on CVD mortality 
as Klatsky and Udaltsova [5] found that the excess mortality seen in nondrinkers is not related to CVD.

This study attempted to account for any "sick quitters" (former drinkers who stopped due to an adverse health condition) through in-depth baseline assessments to rule out underlying disease and adjustment for confounders. In asymptomatic men, especially with risk factors for CVD, exercise testing has been shown to be a valid predictor of future CVD mortality [58] beyond reported risk factors [59]. In addition, we examined if the risk association varied by levels of these risk factors (health status, age, BMI, and fitness status).

\section{Conclusion}

We found a trend towards reduction in risk of all-cause mortality with self-reported alcohol consumption and a reduction in risk of CVD mortality with one to six drinks per week, when adjusting for several potential confounders in a large sample of men. The amount of alcohol consumption associated with a reduced risk of CVD mortality was less than the current public health recommendations of 1-2 drinks per day. A lack of consensus on the amount and type of alcohol for protective effects and other potential harmful consequences of alcohol abuse calls for caution when making public health recommendations for alcohol consumption.

\section{Acknowledgments}

This study was supported by National Institutes of Health grants nos. AG06945, HL62508, and DK088195, and in part by an unrestricted research grant from The CocaCola Company. E. K. Howie's participation in this research was supported in part by research training grant no. T32GM081740 from the National Institutes of Health, National Institute of General Medical Sciences. J. R. Hébert was supported by an Established Investigator Award in Cancer Prevention and Control from the Cancer Training Branch of the National Cancer Institute (K05 CA136975).

\section{References}

[1] L. Arriola, P. Martinez-Camblor, N. Larrañaga et al., "Alcohol intake and the risk of coronary heart disease in the Spanish EPIC cohort study," Heart, vol. 96, no. 2, pp. 124-130, 2010.

[2] J. W. J. Beulens, A. Algra, S. S. Soedamah-Muthu, F. L. J. Visseren, D. E. Grobbee, and Y. van der Graaf, "Alcohol consumption and risk of recurrent cardiovascular events and mortality in patients with clinically manifest vascular disease and diabetes mellitus: the Second Manifestations of ARTerial (SMART) disease study," Atherosclerosis, vol. 212, no. 1, pp. 281-286, 2010.

[3] J. M. Gaziano, T. A. Gaziano, R. J. Glynn et al., "Light-tomoderate alcohol consumption and mortality in the physicians' health study enrollment cohort," Journal of the American College of Cardiology, vol. 35, no. 1, pp. 96-105, 2000.

[4] L. R. Harriss, D. R. English, J. L. Hopper et al., "Alcohol consumption and cardiovascular mortality accounting for possible misclassification of intake: 11-year follow-up of the
Melbourne Collaborative Cohort Study," Addiction, vol. 102, no. 10, pp. 1574-1585, 2007.

[5] A. L. Klatsky and N. Udaltsova, "Alcohol drinking and total mortality risk," Annals of Epidemiology, vol. 17, no. 5, pp. S63S67, 2007.

[6] A. Sadakane, T. Gotoh, S. Ishikawa, Y. Nakamura, and K. Kayaba, "Amount and frequency of alcohol consumption and all-cause mortality in a Japanese population: the JMS cohort study," Journal of Epidemiology, vol. 19, no. 3, pp. 107-115, 2009.

[7] I. Suh, B. J. Shaten, J. A. Cutler, and L. H. Kuller, "Alcohol use and mortality from coronary heart disease: the role of highdensity lipoprotein cholesterol," Annals of Internal Medicine, vol. 116, no. 11, pp. 881-887, 1992.

[8] W. Sun, C. M. Schooling, W. M. Chan, K. S. Ho, T. H. Lam, and G. M. Leung, "Moderate alcohol use, health status, and mortality in a prospective Chinese elderly cohort," Annals of Epidemiology, vol. 19, no. 6, pp. 396-403, 2009.

[9] M. J. Thun, R. Peto, A. D. Lopez et al., "Alcohol consumption and mortality among middle-aged and elderly U.S. adults," The New England Journal of Medicine, vol. 337, no. 24, pp. 1705-1714, 1997.

[10] S. G. Wannamethee and A. G. Shaper, "Lifelong teetotallers, ex-drinkers and drinkers: mortality and the incidence of major coronary heart disease events in middle-aged British men," International Journal of Epidemiology, vol. 26, no. 3, pp. 523531, 1997.

[11] M. A. Collins, E. J. Neafsey, K. J. Mukamal et al., "Alcohol in moderation, cardioprotection, and neuroprotection: epidemiological considerations and mechanistic studies," Alcoholism: Clinical and Experimental Research, vol. 33, no. 2, pp. 206-219, 2009.

[12] A. L. Klatsky, "Alcohol and cardiovascular health," Physiology and Behavior, vol. 100, no. 1, pp. 76-81, 2010.

[13] A. Di Castelnuovo, S. Costanzo, M. B. Donati, L. Iacoviello, and G. de Gaetano, "Prevention of cardiovascular risk by moderate alcohol consumption: epidemiologic evidence and plausible mechanisms," Internal and Emergency Medicine, vol. 5, no. 4, pp. 291-297, 2010.

[14] K. J. Mukamal, E. L. Ding, and L. Djoussé, "Alcohol consumption, physical activity, and chronic disease risk factors: a population-based cross-sectional survey," BMC Public Health, vol. 6, article no. 118, 2006.

[15] N. El-Guebaly, "Investigating the association between moderate drinking and mental health," Annals of Epidemiology, vol. 17, no. 5, pp. S55-S62, 2007.

[16] S. Peele and A. Brodsky, "Exploring psychological benefits associated with moderate alcohol use: a necessary corrective to assessments of drinking outcomes?" Drug and Alcohol Dependence, vol. 60, no. 3, pp. 221-247, 2000.

[17] K. A. Ammar, S. Samee, R. Colligan et al., "Is self-reported moderate drinking in the cardiovascular benefit range associated with alcoholic behavior? A population based study," Journal of Addictive Diseases, vol. 28, no. 3, pp. 243-249, 2009.

[18] G. Corrao, V. Bagnardi, A. Zambon, and C. La Vecchia, "A meta-analysis of alcohol consumption and the risk of 15 diseases," Preventive Medicine, vol. 38, no. 5, pp. 613-619, 2004.

[19] C. Bosetti, A. Altieri, and C. La Vecchia, "Diet and environmental carcinogenesis in breast/gynaecological cancers," Current Opinion in Obstetrics and Gynecology, vol. 14, no. 1, pp. 13-18, 2002.

[20] M. C. Pike, L. N. Kolonel, B. E. Henderson et al., "Breast cancer in a multiethnic cohort in Hawaii and Los Angeles: risk 
factor-adjusted incidence in Japanese equals and in Hawaiians exceeds that in whites," Cancer Epidemiology Biomarkers and Prevention, vol. 11, no. 9, pp. 795-800, 2002.

[21] G. Pöschl, F. Stickel, X. D. Wang, and H. K. Seitz, "Alcohol and cancer: genetic and nutritional aspects," Proceedings of the Nutrition Society, vol. 63, no. 1, pp. 65-71, 2004.

[22] S. N. Blair, H. W. Kohl III, R. S. Paffenbarger Jr., D. G. Clark, K. H. Cooper, and L. W. Gibbons, "Physical fitness and all-cause mortality: a prospective study of healthy men and women," Journal of the American Medical Association, vol. 262, no. 17, pp. 2395-2401, 1989.

[23] E. Giovannucci, G. Colditz, M. J. Stampfer et al., "The assessment of alcohol consumption by a simple self-administered questionnaire," American Journal of Epidemiology, vol. 133, no. 8, pp. 810-817, 1991.

[24] J. R. Hebert, I. S. Ockene, T. G. Hurley et al., "Development and testing of a seven-day dietary recall," Journal of Clinical Epidemiology, vol. 50, no. 8, pp. 925-937, 1997.

[25] C. D. Lee, X. Sui, and S. N. Blair, "Combined effects of cardiorespiratory fitness, not smoking, and normal waist girth on morbidity and mortality in men," Archives of Internal Medicine, vol. 169, no. 22, pp. 2096-2101, 2009.

[26] W. Byun, J. C. Sieverdes, X. Sui et al., "Effect of positive health factors and all-cause mortality in men," Medicine and Science in Sports and Exercise, vol. 42, no. 9, pp. 1632-1638, 2010.

[27] T. G. Pickering, J. E. Hall, L. J. Appel et al., "Recommendations for blood pressure measurement in humans and experimental animals_part 1: blood pressure measurement in humans: a statement for professionals from the subcommittee of professional and public education of the American Heart Association council on high blood pressure research," Hypertension, vol. 45, no. 1, pp. 142-161, 2005.

[28] J. I. Cleeman and C. Lenfant, "The National Cholesterol Education Program. Progress and prospects," Journal of the American Medical Association, vol. 280, no. 24, pp. 2099-2104, 1998.

[29] J. R. Gavin, K. G. M. M. Alberti, M. B. Davidson et al., "Report of the expert committee on the diagnosis and classification of diabetes mellitus," Diabetes Care, vol. 26, supplement 1, pp. S5-S20, 2003.

[30] B. Balke and R. W. Ware, "An experimental study of physical fitness of Air Force personnel," US Armed Forces Medical Journal, vol. 10, no. 6, pp. 675-688, 1959.

[31] M. L. Pollock, R. L. Bohannon, and K. H. Cooper, "A comparative analysis of four protocols for maximal treadmill stress testing," American Heart Journal, vol. 92, no. 1, pp. 3946, 1976.

[32] S. N. Blair, Y. Cheng, and J. Scott Holder, "Is physical activity or physical fitness more important in defining health benefits?" Medicine and Science in Sports and Exercise, vol. 33, no. 6, pp. S379-S399, 2001.

[33] X. Sui, M. J. LaMonte, and S. N. Blair, "Cardiorespiratory fitness as a predictor of nonfatal cardiovascular events in asymptomatic women and men," American Journal of Epidemiology, vol. 165, no. 12, pp. 1413-1423, 2007.

[34] B. Taylor, H. M. Irving, D. Baliunas et al., "Alcohol and hypertension: gender differences in dose-response relationships determined through systematic review and meta-analysis: REVIEW," Addiction, vol. 104, no. 12, pp. 1981-1990, 2009.

[35] S. Kiechl, J. Willeit, W. Poewe et al., "Insulin sensitivity and regular alcohol consumption: large, prospective, cross sectional population study (Bruneck study)," British Medical Journal, vol. 313, no. 7064, pp. 1040-1044, 1996.
[36] E. B. Rimm, P. Williams, K. Fosher, M. Criqui, and M. J. Stampfer, "Moderate alcohol intake and lower risk of coronary heart disease: meta-analysis of effects on lipids and haemostatic factors," British Medical Journal, vol. 319, no. 7224, pp. 1523-1528, 1999.

[37] J. W. J. Beulens, E. B. Rimm, A. Ascherio, D. Spiegelman, H. F. J. Hendriks, and K. J. Mukamal, "Alcohol consumption and risk for coronary heart disease among men with hypertension," Annals of Internal Medicine, vol. 146, no. 1, pp. 10-19, 2007.

[38] M. S. Freiberg, H. J. Cabral, T. C. Heeren, R. S. Vasan, and R. C. Ellison, "Alcohol consumption and the prevalence of the metabolic syndrome in the U.S. A cross-sectional analysis of data from the Third National Health and Nutrition Examination Survey," Diabetes Care, vol. 27, no. 12, pp. 29542959, 2004.

[39] A. Di Castelnuovo, S. Costanzo, V. Bagnardi, M. B. Donati, L. Iacoviello, and G. De Gaetano, "Alcohol dosing and total mortality in men and women: an updated meta-analysis of 34 prospective studies," Archives of Internal Medicine, vol. 166, no. 22, pp. 2437-2445, 2006.

[40] D. Lloyd-Jones, R. J. Adams, T. M. Brown et al., "Heart disease and stroke statistics-2010 update: a report from the American heart association," Circulation, vol. 121, no. 7, pp. e46-e215, 2010.

[41] L. Djoussé, I. M. Lee, J. E. Buring, and J. M. Gaziano, "Alcohol consumption and risk of cardiovascular disease and death in women: potential mediating mechanisms," Circulation, vol. 120, no. 3, pp. 237-244, 2009.

[42] R. Femia, A. Natali, A. L’Abbate, and E. Ferrannini, "Coronary atherosclerosis and alcohol consumption: angiographic and mortality data," Arteriosclerosis, Thrombosis, and Vascular Biology, vol. 26, no. 7, pp. 1607-1612, 2006.

[43] A. H. Lichtenstein, L. J. Appel, M. Brands et al., "Diet and lifestyle recommendations revision 2006: a scientific statement from the American heart association nutrition committee," Circulation, vol. 114, no. 1, pp. 82-96, 2006.

[44] J. Rehm, C. Mathers, S. Popova, M. Thavorncharoensap, Y. Teerawattananon, and J. Patra, "Global burden of disease and injury and economic cost attributable to alcohol use and alcohol-use disorders," The Lancet, vol. 373, no. 9682, pp. 2223-2233, 2009.

[45] A. E. Rogers and M. W. Conner, "Alcohol and cancer," Advances in Experimental Medicine and Biology, vol. 206, pp. 473-495, 1986.

[46] U. A. Hvidtfeldt, J. S. Tolstrup, M. U. Jakobsen et al., "Alcohol intake and risk of coronary heart disease in younger, middleaged, and older adults," Circulation, vol. 121, no. 14, pp. 1589$1597,2010$.

[47] S. Costanzo, A. Di Castelnuovo, M. B. Donati, L. Iacoviello, and G. de Gaetano, "Alcohol consumption and mortality in patients with cardiovascular disease. A meta-analysis," Journal of the American College of Cardiology, vol. 55, no. 13, pp. 1339$1347,2010$.

[48] R. A. Bell, E. J. Mayer-Davis, M. A. Martin, R. B. D’Agostino, and S. M. Haffner, "Associations between alcohol consumption and insulin sensitivity and cardiovascular disease risk factors: the insulin resistance and atherosclerosis study," Diabetes Care, vol. 23, no. 11, pp. 1630-1636, 2000.

[49] C. S. Fuchs, M. J. Stampfer, G. A. Colditz et al., "Alcohol consumption and mortality among women," The New England Journal of Medicine, vol. 332, no. 19, pp. 1245-1250, 1995.

[50] A. L. Klatsky, G. D. Friedman, M. A. Armstrong, and H. Kipp, "Wine, liquor, beer, and mortality," American Journal of Epidemiology, vol. 158, no. 6, pp. 585-595, 2003. 
[51] T. O. Kiviniemi, A. Saraste, J. O. Toikka et al., "A moderate dose of red wine, but not de-alcoholized red wine increases coronary flow reserve," Atherosclerosis, vol. 195, no. 2, pp. e176-e181, 2007.

[52] A. Imhof, I. Plamper, S. Maier, G. Trischler, and W. Koenig, "Effect of drinking on adiponectin in healthy men and women: a randomized intervention study of water, ethanol, red wine, and beer with or without alcohol," Diabetes Care, vol. 32, no. 6, pp. 1101-1103, 2009.

[53] S. N. Blair, W. B. Kannel, H. W. Kohl, N. Goodyear, and P. W. F. Wilson, "Surrogate measures of physical activity and physical fitness. Evidence for sedentary traits of resting tachycardia, obesity, and low vital capacity," American Journal of Epidemiology, vol. 129, no. 6, pp. 1145-1156, 1989.

[54] R. P. Murray, J. E. Connett, S. L. Tyas et al., "Alcohol volume, drinking pattern, and cardiovascular disease morbidity and mortality: is there a u-shaped function?" American Journal of Epidemiology, vol. 155, no. 3, pp. 242-248, 2002.

[55] R. Clarke, C. Frost, R. Collins, P. Appleby, and R. Peto, "Dietary lipids and blood cholesterol: quantitative metaanalysis of metabolic ward studies," British Medical Journal, vol. 314, no. 7074, pp. 112-117, 1997.

[56] C. L. Hart and G. D. Smith, "Alcohol consumption and mortality and hospital admissions in men from the Midspan Collaborative cohort study," Addiction, vol. 103, no. 12, pp. 1979-1986, 2008.

[57] I. H. M. Friesema, P. J. Zwietering, M. Y. Veenstra, J. A. Knottnerus, H. F. L. Garretsen, and P. H. H. M. Lemmens, "Alcohol intake and cardiovascular disease and mortality: the role of pre-existing disease," Journal of Epidemiology and Community Health, vol. 61, no. 5, pp. 441-446, 2007.

[58] L. W. Gibbons, T. L. Mitchell, M. Wei, S. N. Blair, and K. H. Cooper, "Maximal exercise test as a predictor of risk for mortality from coronary heart disease in asymptomatic men," American Journal of Cardiology, vol. 86, no. 1, pp. 53-58, 2000.

[59] G. J. Balady, M. G. Larson, R. S. Vasan, E. P. Leip, C. J. O'Donnell, and D. Levy, "Usefulness of exercise testing in the prediction of coronary disease risk among asymptomatic persons as a function of the Framingham risk score," Circulation, vol. 110, no. 14, pp. 1920-1925, 2004. 


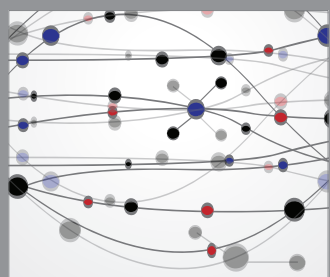

The Scientific World Journal
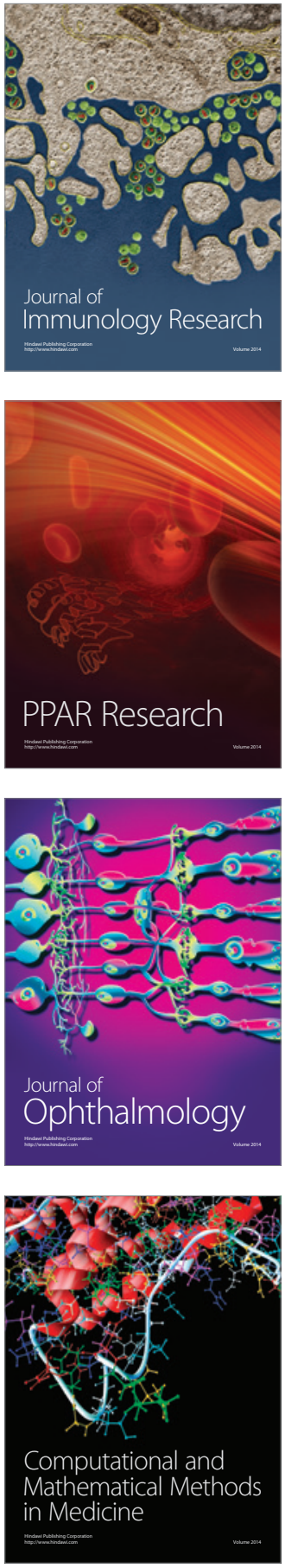

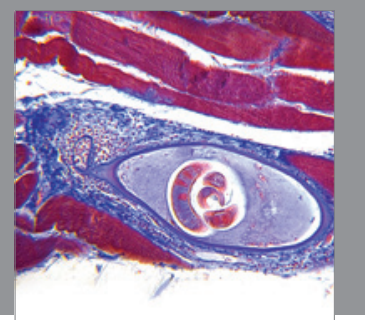

Gastroenterology

Research and Practice
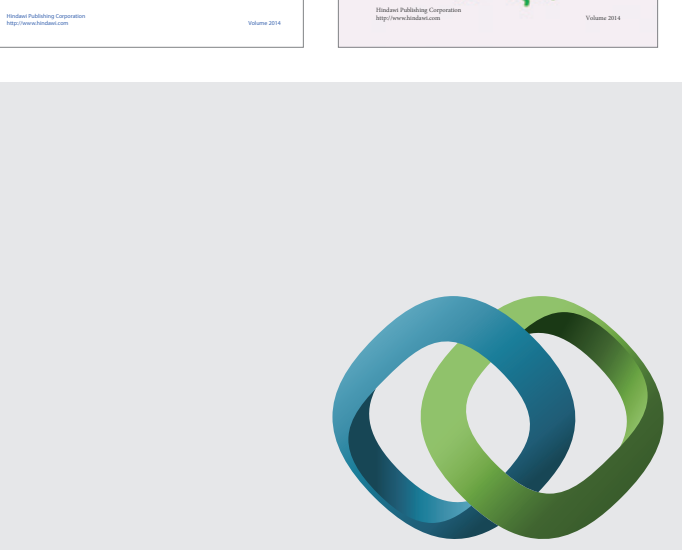

\section{Hindawi}

Submit your manuscripts at

http://www.hindawi.com
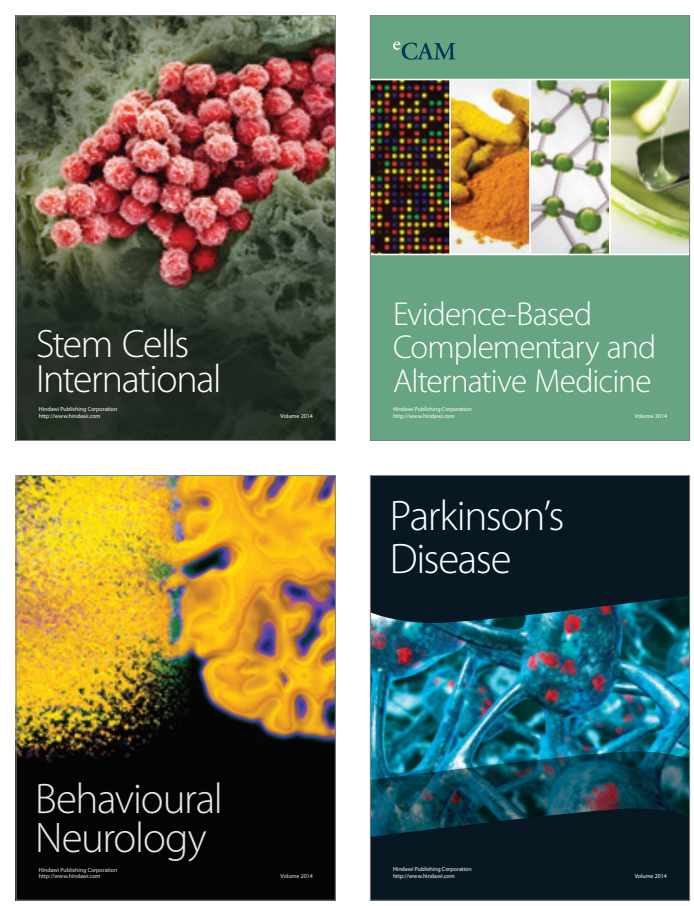

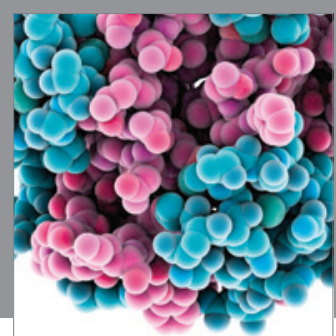

Journal of
Diabetes Research

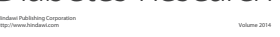

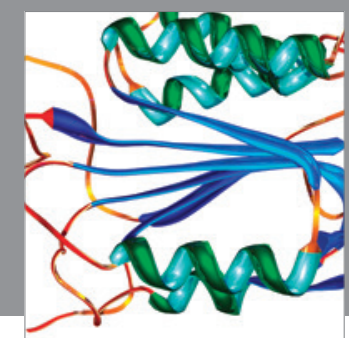

Disease Markers
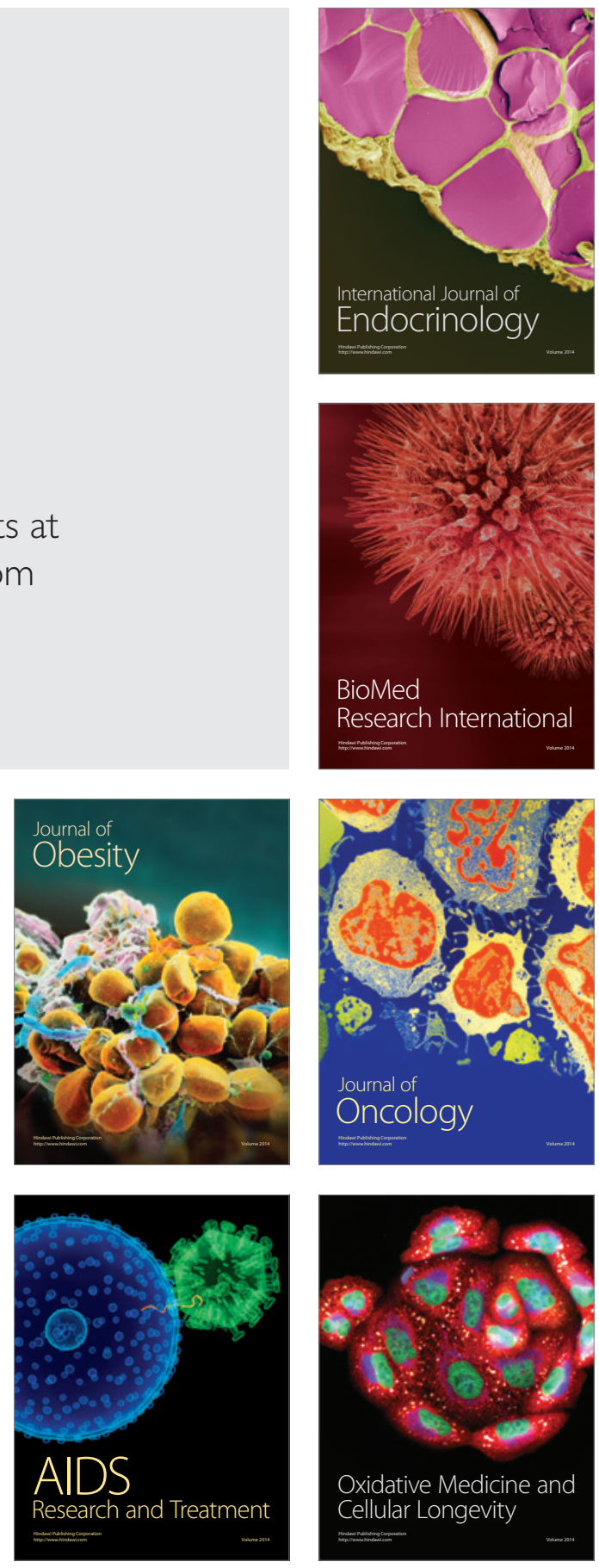